\title{
Review of Envisioning Our Preferred Future: New Services, Jobs, and Directions
}

Jennifer Putnam Davis

Augusta University

\begin{abstract}
Review of Eden, B.L. (Ed.). (2016). Envisioning our preferred future: New services, jobs, and directions. Rowman \& Littlefield.
\end{abstract}

Keywords: academic libraries, library services, digital services

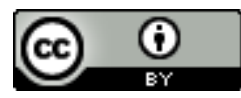

This is an Open Access article distributed under the terms of the Creative Commons Attribution 4.0 International License (http://creativecommons.org/licenses/by/4.0), which permits unrestricted use, distribution, and reproduction in any medium, provided the original work is properly cited. 
Envisioning Our Preferred Future: New Services, Jobs, and Directions, Bradford Lee Eden's eighth volume of Creating the 21st-Century Academic Library series is an ambitious effort that explores both the library's and the librarian's evolving services and responsibilities, as well as their future directions. Each subject could easily employ its own volume in the series, so to present them all here perhaps limits the breadth of study. Nevertheless, Eden offers an extensive list of topics over fourteen essays, some including the perceptions and use of the physical library, government regulations like copyright and the FERPA act, archives, and web services such as data management and digital collections. Readers will appreciate the essays' varying perspectives, but noticeably omitted is that of library staff; the authors are wholly librarians who address their peers and library administrators. Their international voices are refreshing, however. Also admirable is the inclusion of various types of academic libraries; represented are smaller liberal arts to those serving multiple-campuses. Eden graciously makes considerable effort to balance standpoints despite the overwhelming amount of subject matter. Even so, audiences will most likely select what interests them and move on, rather than read the book as a whole.

A reader could approach this volume as a piecemeal exploration of how digital information is impacting today's academic library. Tanackovic, Badurina, and Balog, for example, investigate the effects of accessible electronic information on students' use and perceptions of the physical humanities and social sciences library of a large Croatian research university ("Physical Library Spaces and Services"). The authors present results from a user survey and an ethnographic study to persuasively argue the essential need for physical library space to support both student learning and student activity like peer socializing. Though the scope here will not be applicable to all readers, the 
authors' extensive literature review is notable in illustrating the general shifting trends of how the library is perceived and in what ways the rise of the internet has proliferated these shifts.

While Tanackovic, Badurina, and Balog focus on the physical library space, most essays in Eden's volume address the library's digital changes. A few early essays and one later one discuss emerging web services. Vincci Kwong, from his survey findings, identifies the website, discovery services, and institutional repositories as current popular web services maintained by the library. These conclusions are not solely representative of academic libraries, however, but also include public library respondents, as well ("The Future of Library Web Services”). Mark Stoffan's article "An Overview of Research Data Management" discusses the challenges met by smaller regional and liberal arts libraries in creating such systems. His reflection on the strenuous efforts in gaining faculty interests and institutional support are challenges to which any library can relate. Brown, Evans, and Walsh's impartial evaluation of a collaborative virtual reference service is useful for any reader who is debating about becoming involved with any such service ("QuestionPoint"). In the last article of the collection, “Lessons Learned," Joy Marie Perrin explains the difficulties experienced in creating a digital collection. Her observations on curating metadata to develop effective digital tools as well as to ensure long-term metadata preservation are especially valuable for metadata and cataloging librarians.

The majority of the articles Eden's collected address shifting librarian roles in some way or another. Yang and Fu offer valuable insight on how librarians feel about their own evolving roles. Topher Lawton offers sound advice to all librarians on exhibiting three distinct roles of co-learning in order to more effectively support patrons' needs now that information is continuously being created and disseminated (Intentional Synergy). The three roles are identified as orienteers/constant learners, disrupters/re-framers of information threads, and pilots/information guides, and are best illustrated 
through Lawton's given examples. A few other authors identify new roles for librarians. Rebecca Parker, for example, aptly explains the advent of the research librarian as a response to the overall increased emphasis on institutional research. In this role, the research librarian recognizes academic researchers as a unique user group, with specific needs of applying for grants, reporting government research, and creating an online research profile, among others. Christopher Ewing, another example, discusses librarians as information architects ("Information Architecture"). In this role, librarians design web services like the library by focusing on how to arrange the content, relying on user experience and expectations (p. 145). Though Ewing presents a case study on restructuring a public library's website, his applications are most useful for academic libraries especially as their general overall emphasis continues to evolve to a more user-centered focus and therefore merit inclusion here in Eden's volume. Some authors discuss the growing knowledge base now required to perform traditional responsibilities. Three address technology skills. Jenny Brandon's survey results reveal that librarians are increasingly expected to maintain web pages like research guides, but that they also lack the essential skills to do so (“Librarians as Web Designers”). Ăngel Borrego offers a current literature review for librarians to understand how academics are using social media to disseminate research and knowledge, with specific interest in the scientific community. Lastly, Crowe and Fisher trace the development of archivists' modern roles from the mid-20th century to explain the contemporary digital methods of archival appraisal, acquisitions, and collection management ("Archives and Special Collections in the Digital World"). It is an informative overview of archival work, but readers will want to consult the bibliography to acquire more in-depth information.

Two authors discuss federal regulations in regards to expanding knowledge skills. Eduardo Graziosi Silva astutely argues that reference librarians need to be competent with issues of copyright, 
plagiarism, and authorship to reflect the changes in how information is created, accessed, and used ("The Role of Academic Reference Librarians in Copyright Law"). Similarly, Jennifer Wondracek argues that all librarians should understand the FERPA act, and provides excellent examples of when FERPA might be violated in normal library settings.

The wide-ranging articles in Eden's volume loosely connect in their exploration of how the rise of the internet and digital information are impacting today's academic library and academic librarian. Drawing on specific situations, such as the creation of new library services and new librarian roles, as well as pointing to general observations like shifting perceptions of the physical library and access to library collections, this volume clearly directs readers to the inexorable progress of the twenty-first century academic library. 